\title{
A classe mineralógica das combinações orgânicas associadas ao hidrogênio*
}

\author{
Paulo César Pereira das Neves ${ }^{1}$ \\ nevespc@yahoo.com.br \\ Dione Silva Corrêa ${ }^{1}$ \\ Joel Ricardo Cardoso ${ }^{1}$
}

1 Universidade Luterana do Brasil -Laboratório de Geologia e Mineralogia, Canoas, RS,

\footnotetext{
* Este documento deve ser referido como segue:
}

Neves, P. C. P. das, Corrêa, D. S., Cardoso, J. R. A classe mineralógica das combinações orgânicas associadas ao hidrogênio.Terræ Didatica, 4(1):51-66. <http://www.ige unicamp.br/terraedidatica/>

\begin{abstract}
The mineralogical class of organic compounds associated to hydrogen. Hydrogen, apparently, is the most abundant element present in the Universe, totalizing approximately $88.6 \%$ of known atoms. It exhibits a geochemical abundance of $0.14 \%$ in the Earth crust, occurring also in volcanic gases, aurora borealis, water, human body, hydrocarbons (petroleum, pit coal, peat, and bituminous shale), plants, animals, and a great number of minerals. This work is a contribution to the scientific knowledge of these substances and shows that hydrogen is present in the chemical composition of 40 from the 41 minerals of this interesting mineralogical class of organic compounds. Most of these compounds has significant importance in their corresponding industrial synthetics, mainly in the pharmaceutical and chemical industries. Substances such as oxalates, amides, formiates, acetates, fluorine, nickel-porphyrin, coronene, citrate, purine, dipertene, anthraquinone, phthalimide, mellate and phenanthrene, have multiple applications, such as electropolimerizating films, reagents for synthesis of organic compounds, plasticizers, inputs for the preparation of nanomaterials, separation and concentration of REE and transuranic elements, dietary nutrient supplements, water treatment reagents, coating of valves and additives in cosmetics, metallic paints and plastics in general.
\end{abstract}

\section{KEYWORDS Hydrogen, organic compounds, rare minerals.}

RESUMO O hidrogênio, aparentemente, é o elemento químico mais abundante do Universo, perfazendo aproximadamente $88,6 \%$ de todos os átomos conhecidos. Apresenta abundância geoquímica na crosta terrestre de 0,14\%, ocorrendo ainda nos gases vulcânicos, nas auroras boreais, na água, no corpo humano, nos hidrocarbonetos (petróleo, carvão mineral, turfa e folhelho pirobetuminoso), nos vegetais e animais e, também, em ampla gama de minerais. Este trabalho revisa a interessante classe mineralógica das combinações orgânicas, cujos cristais são relativamente raros. Nesta classe o hidrogênio está presente na composição de 40 das 41 substâncias conhecidas. A maioria dessas substâncias apresenta importância industrial significativa em seus correspondentes sintéticos, principalmente nas indústrias farmacêutica e quimica. Substâncias como os oxalatos, as amidas, os formiatos, os acetatos, o fluoreno, a níquel-porfirina, o coroneno, o citrato, a purina, o diperteno, a antraquinona, a ftalimida, o melato e o fenantreno, têm múltiplas aplicações. Entre as mesmas estão filmes eletropolimerizadores, reagentes para sintese de compostos orgânicos, plastificadores, insumos para preparação de nanomateriais, separação e concentração de ETR e elementos transurânicos, nutriente em dietas complementares, produtos para tratamento de águas, revestimento de válvulas e aditivos em cosméticos, tintas metálicas e plásticos em geral.

PALAVRAS-CHAVE Hidrogênio, combinações orgânicas, minerais raros. 


\section{Introdução}

Este artigo é uma continuação dos trabalhos descritivos sobre a mineralogia associada aos elementos da Tabela Periódica dos Elementos Químicos. Já foi publicada a mineralogia dos elementos químicos do Grupo 11 (Ag-Cu-Au), além do $\mathrm{Pb}$, da Pt, do Li e do Be (Neves et al. 2005, Neves et al. 2006, Ionescu et al. 2007, Neves e Schenato 2007, Neves et al. 2007, Neves et al. 2008b, Neves et al. 2008c).

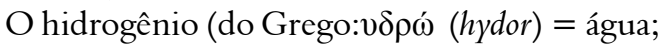

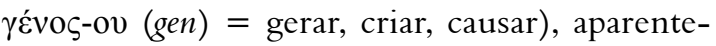
mente, é o elemento químico mais abundante, correspondendo a aproximadamente $88,6 \%$ de todos os átomos do universo e $92 \%$ da massa solar. O elemento, juntamente com o hélio, formou-se durante a nucleogênese, logo após o Big Bang, servindo assim de matéria-prima no processo de nucleossíntese para formar todos os demais elementos químicos naturais (Abell et al. 1985, Barrow 1995, Emiliani 1995, Cordani 2003).

Na Terra, apresenta uma abundância geoquímica na crosta de $0,14 \%$ (Klein 2002), ocorrendo ainda nos gases vulcânicos, nas auroras boreais, na água, no corpo humano, nos hidrocarbonetos (carvão mineral, petróleo, turfa e folhelho pirobetuminoso), nos vegetais e animais e, também, numa ampla gama de minerais. É o primeiro elemento químico da classificação periódica dos elementos, apresentando características únicas. $\mathrm{Na}$ forma gasosa o hidrogênio é muito raro na Terra, pois sendo muito leve, escapa com extrema facilidade do campo gravitacional do planeta.

O hidrogênio, à temperatura ambiente, é um gás diatômico $\left(\mathrm{H}_{2}\right)$ muito inflamável, incolor, inodoro, insípido, insolúvel em água e muito reativo. Foi primeiramente estudado em 1766, pelo químico franco-inglês Henry Cavendish. Entretanto, este elemento, possivelmente, já havia sido isolado pelos químicos britânicos Robert Boyle e Joseph Priestley. Seu nome foi proposto pelo químico francês Antoine-Laurent de Lavoisier, o fundador da Química Moderna, em 1777 (Engel 1896).

Suas propriedades são: número atômico $(\mathrm{Z})$ $=1$; massa atômica $=1,007825035 \mathrm{u}$ (calculada como a média ponderada das massas dos isótopos naturais do hidrogênio); energia de ionização $=$ $1312 \mathrm{~kJ} \cdot \mathrm{mol}^{-1}$; energia de ligação $=435 \mathrm{~kJ} \cdot \mathrm{mol}^{-1}$; composição isotópica $=99,9885 \%$ de ${ }^{1} \mathrm{H}$ (prótio), $0,0115 \%$ de ${ }^{2} \mathrm{H}$ (deutério) e $1.10^{-20} \%$ de ${ }^{3} \mathrm{H}$ (trítio) na crosta terrestre; ${ }^{4} \mathrm{H},{ }^{5} \mathrm{H},{ }^{6} \mathrm{H}$ e ${ }^{7} \mathrm{H}$ (sintéticos); configuração eletrônica do átomo no estado fundamental $=1 \mathrm{~s}^{1} ;$ raio atômico $=25,0 \mathrm{pm}$; raio covalente $=37,0 \mathrm{pm}$; raio de van der Waals $=120,0$ pm; raio iônico do $\mathrm{H}^{-}=208,0$ pm; estrutura cristalina: hexagonal; estados de oxidação: $1^{+}\left(\mathrm{CH}_{4}\right) ; 1^{-}\left(\mathrm{LiAlH}_{4}\right) ; 0\left(\mathrm{UH}_{3}\right)$; massa molecular $\left(\mathrm{H}_{2}\right)=2,01589(4) \mathrm{u}$; densidade $=0,0899 \mathrm{~kg} \cdot \mathrm{m}^{-3}$; estado físico a $25^{\circ} \mathrm{C}$ e $1 \mathrm{~atm}$ : gasoso; cor: incolor; volume molar $=11,42 \times 10^{-6} \mathrm{~m}^{3} / \mathrm{mol}$; temperatura crítica $=33,2 \mathrm{~K}$; eletronegatividade de Pauling $=$ 2,2; ponto de fusão $=-259,0^{\circ} \mathrm{C}(14,15 \mathrm{~K})$; ponto de ebulição $=-252,6^{\circ} \mathrm{C}(20,55 \mathrm{~K})$ (Cotton e Wilkinson 1988, Lee 2003, Gonçalves 2003, Greenwood e Earnshaw 2006).

Até 2008, encontravam-se validados pela IMA (International Mineralogical Association), fundada em 1959, cerca de 2370 minerais contendo hidrogênio em suas composições químicas (nas formas de $\mathrm{OH}$ como na actinolita $\left(\square^{1} \mathrm{Ca}_{2}\left(\mathrm{Mg}, \mathrm{Fe}^{2+}\right)_{5} \mathrm{Si}_{8} \mathrm{O}_{22}(\mathrm{OH})_{2}\right)$ e $\mathrm{H}_{2} \mathrm{O}$ como na ajoíta $\left((\mathrm{K}, \mathrm{Na}) \mathrm{Cu}^{2+}{ }_{7} \mathrm{AlSi}_{9} \mathrm{O}_{24}(\mathrm{OH})_{6} \cdot 3 \mathrm{H}_{2} \mathrm{O}\right)$, mais comumente; e $\mathrm{H}$, mais raramente, como na lintisita $\left(\mathrm{LiCa}_{2} \mathrm{Mn}^{2+}{ }_{2} \mathrm{HSi}_{5} \mathrm{O}_{15}\right)$ ), estando os mesmos distribuídos nas seguintes classes mineralógicas: silicatos (800 espécies), fosfatos (356 espécies), sulfatos (255 espécies), arsenatos (223 espécies), óxidos (206 espécies), carbonatos (142 espécies), boratos (101 espécies), halogenetos (80 espécies), hidróxidos (67 espécies), vanadatos (52 espécies), combinações orgânicas (40 espécies), sulfetos (14 espécies), molibdatos (12 espécies), nitratos (7 espécies), cromatos (6 espécies), tungstatos (5 espécies), iodatos (3 espécies) e selenatos (2 espécies) (Bouska et al. 1998, Lethbridge et al. 2003, Atencio et al. 2004, Mandarino e Back 2004, Jambor et al. 2004, Jambor e Roberts 2004, Jambor e Roberts 2005, Piilonen et al. 2005a, Piilonen et al. 2005b, Piilonen et al. 2005c, Piilonen et al. 2006, Piilonen et al. 2007, Locock et al. 2006a, Locock et al. 2006b, Locock et al. 2006c, Scott Ercit et al. 2006, Scott Ercit et al. 2007, Poirier e Piilonen 2007, Tait et al. 2008, Poirier et al. 2008, Back e Mandarino 2008).

Apesar da grande representatividade de hidrogênio nas substâncias minerais, o elemento não apresenta uma grande quantidade em massa naqueles minerais em que faz parte da composição química. Os dez minerais com maior porcentagem

10 símbolo $\square$, na composição química de um mineral, significa que há uma vacância estrutural na mesma (Mandarino e Back 2004, Back e Mandarino 2008, Neves et al. 2008a) 
em massa de hidrogênio são: evenkita $\left(\mathrm{C}_{24} \mathrm{H}_{50}\right)$ com 14,88 \%; fichtelita $\left(\mathrm{C}_{19} \mathrm{H}_{34}\right)$ com 13,06\%; hartita $\left(\mathrm{C}_{20} \mathrm{H}_{34}\right)$ com $12,48 \%$; gelo $\left(\mathrm{H}_{2} \mathrm{O}\right)$ com $11,19 \%$; flagstaffita $\left(\mathrm{C}_{10} \mathrm{H}_{22} \mathrm{O}_{3}\right)$ com $11,65 \%$; refikita $\left(\mathrm{C}_{20} \mathrm{H}_{32} \mathrm{O}_{2}\right)$ com 10,59\%; simonellita $\left(\mathrm{C}_{19} \mathrm{H}_{24}\right)$ com 9,58\%; melita $\left(\mathrm{Al}_{2}\left[\mathrm{C}_{6}(\mathrm{COO})_{6}\right] \cdot 16 \mathrm{H}_{2} \mathrm{O}\right) \mathrm{com}$ 9,05\%; acetamida $\left(\mathrm{CH}_{3} \mathrm{CONH}_{2}\right) \operatorname{com} 8,53 \%$; oxamita $\left(\left(\mathrm{NH}_{4}\right)_{2} \mathrm{C}_{2} \mathrm{O}_{4} \cdot \mathrm{H}_{2} \mathrm{O}\right)$ com 7,63\%. Desses, apenas o gelo não faz parte da classe mineralógica das combinações orgânicas.

Muito embora um grande número de minerais apresentem hidrogênio em suas composições químicas o elemento não é produzido industrialmente a partir desses compostos. Sua produção industrial em grande escala se dá a partir da água, do biogás gerado por biomassa, do gás natural, do etanol, do biodiesel e da glicerina (Greenwood e Earnshaw 2006).

$\mathrm{O}$ artigo tem por objetivo a divulgação científica da importante classe das combinações orgânicas, minerais que contêm significativas porcentagens de hidrogênio em suas composições químicas. Visa também contribuir com a cultura química e geológica desses compostos, praticamente desconhecidos como espécies minerais pela grande maioria da comunidade acadêmico-científica. Outro fator que concorre é o fato dessas informações não se encontrarem disponibilizadas em uma mesma publicação, estando, na maioria das vezes, dispersas em bibliografia especializada. Também é colocada a nomenclatura química desses compostos, o que não é abordado nas diversas publicações gerando muitas confusões de ordem taxonômica. Adotou-se como base nomenclatural Strunz e Nickel (2001).

A Classe consiste em 41 espécies mineralógicas validadas pela IMA (International Mineralogical Association), na qual somente o natroxalato $\left(\mathrm{Na}_{2} \mathrm{C}_{2} \mathrm{O}_{4}\right)$ não apresenta hidrogênio em sua composição química. Um oxalato de manganês diidratado, que ocorre como cristais monoclínicos e composição $\mathrm{Mn}\left(\mathrm{C}_{2} \mathrm{O}_{4}\right) \cdot 2 \mathrm{H}_{2} \mathrm{O}$, em incrustrações castanhas e grãos anédricos, associado com humboldtina, recobrindo óxidos de ferro, descrito em Ortenbergt, Offenburg, Alemanha e em pegmatitos de Minas Gerais, Brasil, foi aprovado pela $I M A$ em 2004, correspondendo ao mineral lindbergita (Walenta 2003 in Jambor e Roberts 2004, Atencio et al. 2004).

\section{COMBINAÇÕES ORGÂNICAS}

Um mineral é formado, geralmente, por processos inorgânicos, ou seja, com uma origem a partir de processos geológicos. Entretanto, de acordo com definições tradicionais (Betejtin 1970, Milovsky e Kononov 1985, Klein e Hurlbut Jr. 1998, Klein 2002), substâncias puramente biogênicas, produzidas por processos biológicos na origem, podem ser incluídas também na definição de mineral (Nickel 1985), desde que respeitem as demais condições preestabelecidas. Exemplos dessas substâncias são as conchas de moluscos e recifes de coral (aragonita, calcita e vaterita $-\mathrm{CaCO}_{3}$ ). Tais substâncias, apesar de serem geradas por organismos, apresentam compostos químicos idênticos às formas naturais de origem inorgânica. Assim, se algum processo geológico agir sobre a matéria orgânica, o produto pode ser aceito como um mineral (Neves et al. 2008a).

As combinações orgânicas validadas como minerais correspondem a um grupo de misturas mal definidas, cujas composições químicas apresentam combinações com o carbono. Seus cristais naturais apresentam apenas interesse científico, pois encontram-se, não raras vezes, na natureza, em distribuições pontuais com volumes muito baixos, o que impossibilita a possibilidade de exploração econômica de seus depósitos. Entretanto, alguns de seus correspondentes sintéticos apresentam significativa importância econômica, sendo substâncias orgânicas relevantes para a indústria química e farmacêutica, em seus diversos segmentos.

Os minerais que fazem parte da classe e que possuem hidrogênio em suas composições químicas são:

\section{Abelsonita}

$\mathrm{C}_{31} \mathrm{H}_{32} \mathrm{~N}_{4} \mathrm{Ni}$ (níquel-porfirina) - validado pela IMA em 1975. Sistema Triclínico. Massa molar = 519,31 g. mol $^{-1}$, com 6,21 \% de hidrogênio. Aspectos dos cristais: aglomerados foliáceos, laminados, platiformes com coloração variável do rosa-púrpura ao vermelho-acastanhado. Ambiente gerador: mineral gerado por sais derivados de ácidos orgânicos, que ocorre ao longo de fraturas de folhelhos ricos em querogênio, em associação com albita, ortoclásio, pirita, quartzo, dolomita, analcima e micas autigênicas ricas em K e Fe. Principais ocorrências: Formação Green River, Uintah County, Utah e bacia de Piceance Creek, Rio Blanco, Colorado, Estados 
Unidos da América. Usos do correspondente sintético: filmes eletropolimerizadores e detecção de óxido nítrico em soluções aquosas (Milton et al. 1978, Mason et al. 1989, Trevin et al. 1996, Mandarino e Back 2004, Back e Mandarino 2008).

\section{Acetamida}

$\mathrm{H}_{3} \mathrm{CONH}_{2}$ (amida de ácido acético ou etanoamida) - validado pela IMA em 1974. Sistema Trigonal. Massa molar $=59,07$ g. $\mathrm{mol}^{-1}, \operatorname{com} 8,53 \%$ de hidrogênio. Aspecto dos cristais: incrustrações esbranquiçadas, cinzentas e incolores; agregados granulares às vezes prismáticos, estalactíticos. Ambiente gerador: pilhas de rejeito de carvão mineral em pontos ricos em amônia, nos períodos de seca (mineral sazonal), em associação com sal amoníaco e, também, em folhelhos negros, em temperaturas entre $50-150^{\circ} \mathrm{C}$. Como é uma substância combustível, em elevadas temperaturas pode emitir gases tóxicos (NO, $\mathrm{CO}, \mathrm{CO}_{2}$ ). Principais ocorrências: mina de carvão de Chervonograd, bacia de L'vov-Volynskii, Ucrânia; Shamokin, Northcumberland, Pensilvânia, Estados Unidos da América; encontra-se também entre os compostos orgânicos descritos recentemente para o centro da Via Láctea. Usos do correspondente sintético: síntese de compostos orgânicos e plastificador (produção de concreto, giz, plásticos). É um possível agente carcinogênico (Denne e Small 1971, Fleischer et al. 1976, Kennedy e Sherman 1986, Mandarino e Back 2004, Hollis et al. 2006, Back e Mandarino 2008).

\section{Calclacita}

$\mathrm{Ca}\left(\mathrm{CH}_{3} \mathrm{COO}\right) \mathrm{Cl} .5 \mathrm{H}_{2} \mathrm{O}$ (cloro-acetato de cálcio pentaidratado) - validado pré-IMA (descoberto em 1945). Sistema Monoclínico. Massa molar $=$ 350,18 g.mol ${ }^{-1}$, com 6,62 \% de hidrogênio. Aspecto dos cristais: eflorescências de coloração branca. Ambiente gerador: mineral de rara ocorrência somente encontrado recobrindo rochas calcárias e fósseis expostos em museus, provavelmente devido à interação do ácido acético, proveniente da madeira carvalho, existente nas guarnições do material exposto nesses locais com a matriz calcária do acervo fossilífero. Também se forma sobre peças cerâmicas. Principal ocorrência: materiais do repositório do Museu Imperial de História Natural, Bruxelas, Bélgica. Usos: somente a forma natural é utilizada como material museológico e em coleções de minerais (Fleischer 1947, van Tassel 1958, Mandarino e Back 2004, Branco e Chaves 2006, Linnow et al. 2007, Back e Mandarino 2008).

\section{Caoxita}

$\mathrm{Ca}\left(\mathrm{C}_{2} \mathrm{O}_{4}\right) \cdot 3 \mathrm{H}_{2} \mathrm{O}$ (oxalato de cálcio triidratado) - validado pela IMA em 1997. Sistema Triclínico. Massa molar $=182,14$ g. $\mathrm{mol}^{-1}, \operatorname{com} 3,32 \%$ de hidrogênio. Aspecto dos cristais: agregados esferulíticos com coloração variável de incolor a branca. Ambiente gerador: mineral encontrado em fraturas de metacherts (rochas metamórficas silicosas) preenchidas por mineralizações de manganês e bário e, em ofiolitos, em associação com quartzo, barita, braunita e óxido de manganês. Principal ocorrência: mina de Cherchiara, Borghetto Vara, Faggiona, Ligúria, Itália. Seus cristais são importantes componentes da formação dos cálculos renais. Usos do correspondente sintético: oxalatos com pequena solubilidade apresentam especificações industriais como precursores na síntese de materiais cerâmicos supercondutores a altas temperaturas, preparação de nanomateriais e separação e concentração de ETR que são os Elementos Terras Raras ou lantanídeos, isto é, grupo de elementos químicos com número atômico entre 57 e 71, começando por lantânio (ETR leve) e terminando por lutécio (ETR pesado), com comportamento geoquímico muito semelhante, o que faz com que tendam a estar sempre juntos na natureza, substituindo-se nas estruturas cristalinas e, elementos transurânicos (Khan et al. 1997, Basso et al. 1998, Jambor et al. 1998, Mandarino e Back 2004, Atencio 2004, Back e Mandarino 2008).

\section{Carpatita}

$\mathrm{C}_{24} \mathrm{H}_{12}$ (coroneno) - validado pré-IMA (descoberto em 1955). Sistema Monoclínico. Massa molar $=300,36 \mathrm{~g} \cdot \mathrm{mol}^{-1}$, com 4,03\% de hidrogênio. Aspecto dos cristais: agregados radiais aciculares e fibrosos com coloração variável do verde-pálido ao amarelo. Ambiente gerador: hidrotermalismo na zona de contato de dioritos pórfiros com argilitos, em associação com cinábrio, quartzo e idrialina ou curtisita, uma substância betuminosa resultante da alteração de compostos mercurosos. Principais ocorrências: Olenevo, Transcárpatos, Ucrânia; minas de mercúrio 4 de Julho, Nova Ídria e Los Picachos, São Benito, Califórnia, Estados Unidos da América. Usos do correspondente sintético: obtido no processo de refinamento do petróleo, apresenta apenas interesse teórico pela química orgânica, devido a sua aromaticidade. A substância merece cuidado por ser causadora de prejuízos ao DNA dos mamíferos (Fleischer 1957, Simoneit e Fetzer 1996, Mandarino e Back 2004, Echigo et al. 2007, Back e Mandarino 2008). 


\section{Coskrenita}

$(\mathrm{Ce}, \mathrm{Nd}, \mathrm{La})_{2}\left(\mathrm{SO}_{4}\right)_{2}\left(\mathrm{C}_{2} \mathrm{O}_{4}\right) \cdot 12 \mathrm{H}_{2} \mathrm{O}$ (sulfo-oxalato de cério octaidratado) - validado pela IMA em 1996. Sistema Triclínico. Massa molar $=706,61 \mathrm{~g} \cdot \mathrm{mol}^{-1}$, com 2,28 \% de hidrogênio. Aspecto dos cristais: em forma de cunhas tabulares com colorações variáveis do rosa, azul-pálido ao amarelo-creme. Ambiente gerador: oxidação de filitos piritosos, com evaporação de soluções sulfatadas em solos de terrenos escarpados, em associação evaporítica com epsomita e apjohnita, sendo que as terras raras, possivelmente, são derivadas das monazitas e dos xenotímios. Principal ocorrência: Alum Cave Bluff, Great Smoky Mountains National Park, Servier, Tennessee, Estados Unidos da América. Usos do correspondente sintético: idênticos aos de caoxita (Peacor et al. 1999, Jambor et al. 2000b, Mandarino e Back 2004, Atencio 2004, Back e Mandarino 2008).

\section{Dashkovaíta}

$\mathrm{Mg}(\mathrm{HCOO})_{2} \cdot 2 \mathrm{H}_{2} \mathrm{O}$ (formiato de magnésio diidratado) - validado pela IMA em 2000. Sistema Monoclínico. Massa molar: 172,49 g. mol $^{-1}$, com 3,33 \% de hidrogênio. Aspecto dos cristais: agregados fibrosos de coloração branca. Ambiente gerador: veios hidrotermais de mármores dolomíticos em serpentinitos, em associação com shabynita, iowaíta, ekaterinita, korshunovskita, halita e hidromagnesita. Principais ocorrências: depósitos de boro de Korshunovskoye, Irkutsk e Solongo B, Buriátia, Transbaikália, Sibéria, Rússia. Usos: somente a forma natural é utilizada como material museológico e em coleções de minerais (Jambor e Roberts 2001, Mandarino e Back 2004, Back e Mandarino 2008).

\section{Earlandita}

$\mathrm{Ca}_{3}\left(\mathrm{C}_{6} \mathrm{H}_{5} \mathrm{O}_{7}\right)_{2} \cdot 4 \mathrm{H}_{2} \mathrm{O}$ (citrato de cálcio tetraidratado) - validado pré-IMA (descoberto em 1936). Sistema Monoclínico. Massa molar $=570,50$ g. $\mathrm{mol}^{-1}$, com 3,18 \% de hidrogênio. Aspecto dos cristais: nódulos finamente granulados a verrucosos, com colaração variável do branco ao amareloclaro. Ambiente gerador: sedimentos inconsolidados de fundo oceânico, em associação com quartzo e restos de foraminíferos. Principal ocorrência: testemunho de fundo $\left(71^{\circ} 22^{\prime} \mathrm{S} ; 16^{\circ} 34^{\prime} \mathrm{W}\right.$, a $\left.2,58 \mathrm{Km}\right)$ do mar de Weddell, Península Antártica, Antártica. Usos do correspondente sintético: nutriente em dietas complementares para o tratamento de acloridria estomacal e redução da incidência de cálculos renais, além do tratamento de águas. Esta substância pode ser muito tóxica para os sistemas respiratório e epitelial, dos mamíferos em geral (Pogaines e Shaw 1957, Mandarino e Back 2004, Back e Mandarino 2008).

\section{Evenkita}

$\mathrm{C}_{24} \mathrm{H}_{50}$ (n-tetracosano) - validado pré-IMA (descoberto em 1953). Sistema Ortorrômbico. Massa molar: 338,66 g. $\mathrm{mol}^{-1}$, com 14,88 \% de hidrogênio (maior massa em hidrogênio entre todos os minerais). Aspecto dos cristais: grânulos em forma de flocos, tabulares, com coloração variável do incolor, branco, amarelo esbranquiçado ao amarelo-esverdeado. Ambiente gerador: rochas ígneas efusivas, preenchendo geodos juntamente com quartzo e calcedônia e, em cavidades mineralizadas em associação com quartzo, pirita, pirrotita, esfalerita, galena, calcopirita e calcita. Principais ocorrências: região de Evenki, baixo vale do rio Tunguska, Sibéria, Rússia; Merník, Slavik, Presov, Eslováquia; Curbans, Hautes-Alpes, Côte d'Azur, França. Usos: somente a forma natural é utilizada como material museológico e em coleções de minerais (Fleischer 1955, Strunz e Contag 1965, Mandarino e Back 2004, Back e Mandarino 2008).

\section{Fichtelita}

$\mathrm{C}_{19} \mathrm{H}_{34}$ (dimetil-isopropil-peridrofenantreno) - validado pré - IMA (descoberto em1841). Sistema Monoclínico. Massa molar $=262,48 \mathrm{~g} \cdot \mathrm{mol}^{-1}, \mathrm{com}$ 13,06 \% de hidrogênio. Aspecto dos cristais: tabulares com coloração variável do incolor ao branco. Ambiente gerador: em madeiras fossilizadas de pinheiros nas turfeiras e em sedimentos marinhos modernos, ricos em matéria orgânica. Principais ocorrências: Redwitz e Marktredwitz, montanhas Fichtel, Bavária, Alemanha; Sobeslav, República Tcheca; Montes Magura, Zilina, Eslováquia. Usos: somente a forma natural é utilizada como material museológico e em coleções de minerais (Mace e Peterson 1995, Mandarino e Back 2004, Back e Mandarino 2008).

\section{Flagstaffita}

$\mathrm{C}_{10} \mathrm{H}_{22} \mathrm{O}_{3}$ (cis-terpeno hidratado) - validado pré-IMA (descoberto em 1920). Sistema Ortorrômbico. Massa molar $=190,28 \mathrm{~g} \cdot \mathrm{mol}^{-1}$, com $11,65 \%$ de hidrogênio. Aspecto dos cristais: prismáticos, drusiformes, incolores. Ambiente gerador: fendas radiais de troncos de árvores fossilizadas recobertas por sedimentos coluviais, em depósitos detritais aluviais. Principal ocorrência: montanhas São Francisco, Flagstaff, Coconino, Arizona, Estados Unidos da América. Usos: somente a forma 
natural é utilizada como material museológico e em coleções de minerais (Guild 1920, Guild 1921, Fleischer 1965, Strunz e Contag 1965, Mandarino e Back 2004, Branco e Chaves 2006, Back e Mandarino 2008).

\section{Formicaíta}

$\mathrm{Ca}\left(\mathrm{HCO}_{2}\right)_{2}$ (formiato de cálcio) - validado pela IMA em 1998. Sistema Tetragonal. Massa molar $=$ 130,11 g.mol-1 ${ }^{-1}$ com 1,55 \% de hidrogênio. Aspecto dos cristais: agregados tabulares microscópicos, às vezes coloformes, com coloração variável do branco ao azul-claro. Ambiente gerador: veios hidrotermais que cortam minérios de kurchatovita e sakhaíta (depósito Solongo B), em associação com calcita, lizardita, pentaidroborita, hexaidroborita e vimsita; veios de mármores escarnitizados (Novofrolovskoye), em associação com calcita, vesuvianita, pentaidroborita, calciborita, uralborita e johnbaumita. Principais ocorrências: depósito de boro de Solongo B, Buriátia e depósito cuprífero de Novofrolovskoye, montes Urais, Rússia. Usos do correspondente sintético: revestimento de válvulas e indústria farmacêutica (Jambor et al. 2000a, Mandarino e Back 2004, Back e Mandarino 2008).

\section{Glushinskita}

$\mathrm{Mg}\left(\mathrm{C}_{2} \mathrm{O}_{4}\right) \cdot 2 \mathrm{H}_{2} \mathrm{O}$ (oxalato de magnésio diidratado) - validado pela IMA em 1987. Sistema Monoclínico. Massa molar = 148,36 g. $\mathrm{mol}^{-1}, \mathrm{com}$ 2,72 $\%$ de hidrogênio. Aspecto dos cristais: agregados granulares, piramidados, com coloração variável do branco ao incolor. Ambiente gerador: interfácie de colônias liquênicas e serpentinitos, devido à reação entre minerais magnesianos e ácido oxálico secretado pelos líquens (Escócia), em associação com whewellita, crisotilo e quartzo. Veios de carvão impregnados por ácido acético natural (Rússia), em associação com whewelita, weddelita, calcita, dolomita, stepanovita e zhemchuzhnikovita. Superfície das plantas do deserto (Israel) e depósitos gipsíferos (Estados Unidos da América). Principais ocorrências: bacia carbonífera do Lena, Yakutia, Rússia; São Simão, Cochise, Arizona, Estados Unidos da América; Mill of Johnston, Insch, Escócia; bacia do lago Huleh, vale do rio Jordão, Israel. Usos do correspondente sintético: idênticos aos de caoxita (Wilsor et al. 1980, Fleischer e Pabst 1981, Cowgill 1989, Mandarino e Back 2004, Atencio 2004, Branco e Chaves 2006, Back e Mandarino 2008).

\section{Guanina}

$\mathrm{C}_{5} \mathrm{H}_{3}\left(\mathrm{NH}_{2}\right) \mathrm{N}_{4} \mathrm{O}$ (2-amino-6-hidroxipurina) - validado pela IMA em 1973. Sistema Monoclí- nico. Massa molar $=151,13$ g. $\mathrm{mol}^{-1}$, com 3,33\% de hidrogênio. Aspecto dos cristais: incrustrações finamente granuladas de coloração branca. Ambiente gerador: acúmulo de excrementos de pássaros marinhos e de quirópteros em cavernas, podendo estar em associação com aphthitalita, archerita, bifosfamita, brushita, calcita, estercorita, gipsita, halita, hannayíta, monetita, mundrabillaíta, newberyíta, oxamita, singenita, taylorita, weddelita e whitelockita. Principais ocorrências: ilha Chincha do Norte, Peru; cavernas de Murra-el-Elevyn, Cocklebiddy e Petrogale, Madura Motel, Austrália. Usos do correspondente sintético: material aditivo em cosméticos, tintas metálicas e plásticos (Bridge 1973a, Bridge 1974, Miyakawa et al. 2000, Mandarino e Back 2004, Back e Mandarino 2008).

\section{Hartita}

$\mathrm{C}_{20} \mathrm{H}_{34}$ (diperteno) - validado pré-IMA (descoberto em 1841). Sistema Triclínico. Massa molar: 279,44 g.mol-1 ${ }^{-1}$, com 12,48 \% de hidrogênio. Aspecto dos cristais: lamelares, maciços, com coloração variável do incolor, branco ao amarelo. Ambiente gerador: interior de fraturas de linhitos e em troncos de árvores silicificados, em associação com siderita e simonellita em locais limonitizados. Principais ocorrências: Hart, Gloggnitz, Áustria; mina Santa Bárbara, Terni, Castelnuovo di Valdarno e Fognano, Montepulciano, Siena, Toscana, Itália; mina de carvão de Bílina, Boêmia, República Tcheca; Oberdorf, Turnau, Estíria, Alemanha. Usos do correspondente sintético: indústria farmacêutica como anti-fungicida e antibiótico (Holden 1922, Bouska et al. 1998, Neves et al. 2008a).

\section{Hoelita}

$\mathrm{C}_{14} \mathrm{H}_{8} \mathrm{O}_{2}$ (9,10-antraquinona) - validado préIMA (descoberto em 1922). Sistema Monoclínico. Massa molar $=208,22$ g.mol ${ }^{-1}, \operatorname{com} 3,87 \%$ de hidrogênio. Aspecto dos cristais: prismáticos, com coloração variável do amarelo ao amarelo-esverdeado. Ambiente gerador: em fraturas de linhitos, devido à combustão de camadas carboníferas, geralmente em associação com alunogênio, enxofre nativo, godovikovita, gipsita, halotriquita, letovicita, mascagnita, sal amoníaco, selênio nativo e tschermiguita. Principais ocorrências: monte Pirâmide, ilha de Spitsbergen, Svalbard, Noruega; mina de Carola, Freital, Dresden, Saxônia, Alemanha; mina Nejedly, Kladno, Boêmia e mina de carvão Katerina, Rodvanice, Trutnov, República Tcheca. Usos do correspondente sintético: exobiologia e indústria farmacêutica (Mandarino e Back 2004, Jehlica et al. 
2008, Back e Mandarino 2008, http://www.mindat. org/min-1915.html/).

\section{Hoganita}

$\mathrm{Cu}\left(\mathrm{CH}_{3} \mathrm{COO}\right)_{2} \cdot \mathrm{H}_{2} \mathrm{O}$ (acetato de cobre monoidratado) - validado pela IMA em 2002. Sistema Monoclínico. Massa molar $=201,35$ g. $\mathrm{mol}^{-1}, \mathrm{com}$ 3,95\% de hidrogênio. Aspecto dos cristais: prismáticos com coloração verde-azulada. Ambiente gerador: mineral secundário formado por reação de oxidação entre minerais metálicos e matéria orgânica proveniente de folhas vegetais mortas, em associação com paceíta, linarita, malaquita, azurita, smithsonita, cerussita, goethita, hematita e quartzo. Principal ocorrência: depósito de Ag-Pb-Zn de Potosi, Broken Hill, Nova Gales do Sul, Austrália. Usos do correspondente sintético: fungicida, pigmento verde, fonte de cobre em síntese inorgânica, catalisador em síntese orgânica e agente oxidante (Kirchner e Fernando 2000, Hibbs et al. 2002, Mandarino e Back 2004, Back e Mandarino 2008).

\section{Humboldtina}

$\mathrm{Fe}^{2+} \mathrm{C}_{2} \mathrm{O}_{4} \cdot 2 \mathrm{H}_{2} \mathrm{O}$ (oxalato de ferro II diidratado - Figura 1) - validado pré-IMA (descoberto em 1821). Sistema Monoclínico. Massa molar $=$ 179,90 g.mol ${ }^{-1}, \operatorname{com} 2,24 \%$ de hidrogênio. Aspecto dos cristais: prismáticos, botrioidais, massas fibrosas, com coloração variável do amarelo ao amareloacastanhado. Ambiente gerador: estratos de linhito em depósitos carboníferos e, também, em pegmatitos graníticos, como produto do hidrotermalismo, podendo estar em associação com goethita, minguzzita, tschermiguita, quartzo, turmalinas, gipsita, cassiterita e lindbergita. Principais ocorrências: Korozluky, Bilin e Lomnice, Zapadocesky Kraj, Boêmia, República Tcheca; pegmatito Pombas,
Santa Maria de Itabira, Minas Gerais, Brasil; Capo Calamita, ilha de Elba, Toscana, Itália; Ortenberg, Offenburg, Floresta Negra, Alemanha. Usos do correspondente sintético: idênticos aos de caoxita (Fleischer 1956, Mazzi e Gavarelli 1957, Jambor e Roberts 2004, Mandarino e Back 2004, Atencio 2004, Back e Mandarino 2008).

\section{Idrialita}

$\mathrm{C}_{22} \mathrm{H}_{14}$ (dimetil-benzeno-fenantreno - Figura 2) - validado pré-IMA (descoberto em 1832). Sistema Ortorrômbico. Massa molar $=278,35$ g. $\mathrm{mol}^{-1}$, com 5,07 \% de hidrogênio. Aspecto dos cristais: tabulares, com coloração variável do incolor, castanho-claro ao amarelo-esverdeado. Ambiente gerador: minas de mercúrio, formado possivelmente por pirólise de material orgânico próximo de fontes quentes ou, então, por fluídos hidrotermais, provavelmente por uma mistura complexa de hidrocarbonetos aromáticos policíclicos, em associação com cinábrio, pirita, gipsita, quartzo e argilas (Idrija) e metacinábrio, realgar e opala (Skaggs Springs). Principais ocorrências: Idrija (Ídria, Carniola), Eslovênia; Skaggs Springs, Sonoma, minas de Mirabel, Helen e Research, Lake County e mina de Knoxville, Napa, Califórnia, Estados Unidos da América. Usos: somente a forma natural é utilizada como material museológico e em coleções de minerais (Strunz e Contag 1965, Mandarino e Back 2004, Back e Mandarino 2008).

\section{Kladnoíta}

$\mathrm{C}_{6} \mathrm{H}_{4}(\mathrm{CO})_{2} \mathrm{NH}$ (ftalimida - ácido ftálico) validado pré-IMA (descoberto em 1942). Sistema Monoclínico. Massa molar $=147,13 \mathrm{~g} \cdot \mathrm{mol}^{-1}, \mathrm{com}$ $0,69 \%$ de hidrogênio. Aspecto dos cristais: tabulares, prismáticos, com coloração variável do incolor
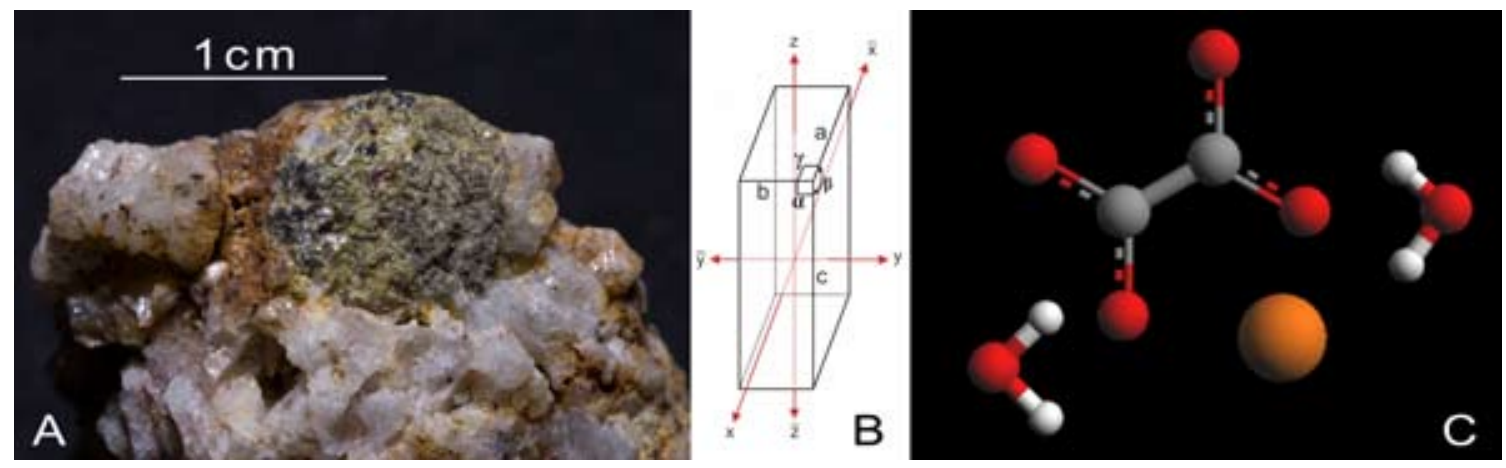

Figura 1 - Cristais de humboldtina (CMULBRA 00725), pegmatito Pombas, Santa Maria do Itabira, MG, Brasil (A), modelo de sua cela unitária e constantes cristalográficas (B) e modelo da estrutura do oxalato de ferro II diidratado (C) (Fonte: Laboratório de Geologia e Mineralogia, Curso de Química, ULBRA 

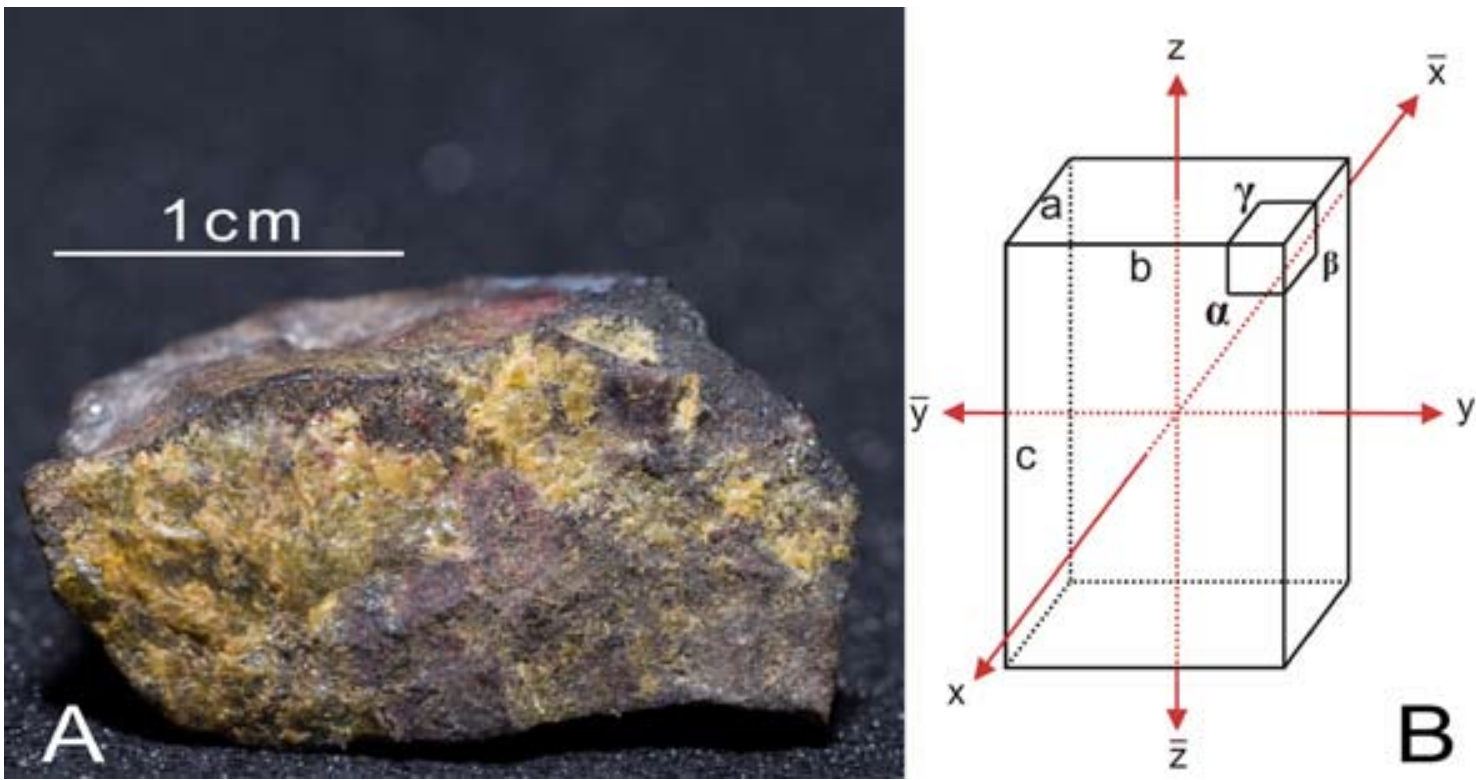

Figura 2 - Cristais de idrialita, Idrija, Carniola, Eslovênia (CMULBRA 00745) (A), modelo de sua cela unitária e constantes cristalográficas (B) (Fonte: Laboratório de Geologia e Mineralogia, Curso de Química, ULBRA)

ao branco. Ambiente gerador: ação do fogo sobre pilhas de rejeitos carboníferos. Principais ocorrências: Libŭsín, bacia carbonífera de Kladno, Stredocesky, Boêmia e Radvanice, República Tcheca. Usos do correspondente sintético: material anticorrosivo (Fleischer 1946, Mazat 1972, Mandarino e Back 2004, Back e Mandarino 2008).

\section{Kratochvilita}

$\mathrm{C}_{13} \mathrm{H}_{10}$ (fluoreno) - validado pré-IMA (descoberto em 1937). Sistema Ortorrômbico. Massa molar: 166,22 g.mol ${ }^{-1}$, com 6,06 \% de hidrogênio. Aspecto dos cristais: maciços de coloração branca. Ambiente gerador: ação de fogo sobre rejeitos carboníferos ou sobre folhelhos piritosos. Principal ocorrência: mina Schoeller, Nejedly, bacia carbonífera de Kladno, Stredocesky, Boêmia, República Tcheca. Usos do correspondente sintético: produção de tintas, plásticos e pesticidas (Brow e Bortner 1954, Mandarino e Back 2004, Back e Mandarino 2008, http://rruff.geo.arizona.edu/doclib/hom/ kratochvilite.pdf/).

\section{Levinsonita - ( $(Y)$}

$(\mathrm{Y}, \mathrm{Nd}, \mathrm{Ce}) \mathrm{Al}\left(\mathrm{SO}_{4}\right)_{2}\left(\mathrm{C}_{2} \mathrm{O}_{4}\right) \cdot 12 \mathrm{H}_{2} \mathrm{O}$ (aluminossulfo-oxalato de ítrio dodecaidratado) - validado pela IMA em 1996. Sistema Monoclínico. Massa molar $=623,48$ g.mol ${ }^{1}$, com 3,88 \% de hidrogênio. Aspecto dos cristais: agregados prismáticos incolores. Ambiente gerador: mineral supergênico formado por alteração de filitos piritosos, sendo as terras raras, possivelmente, derivadas das monazi- tas e xenotímios, estando

em associação evaporítica com zugshunstita-(Ce), epsomita e halotriquita. Principal ocorrência: Alum Cave Bluff, Great Smoky Mountains National Park, Servier, Tennessee, Estados Unidos da América. Usos do correspondente sintético: idênticos aos de caoxita (Rouse et al. 2001, Jambor e Roberts 2001, Mandarino e Back 2004, Atencio 2004, Back e Mandarino 2008).

\section{Lindbergita}

$\mathrm{Mn}\left(\mathrm{C}_{2} \mathrm{O}_{4}\right)_{2} \cdot \mathrm{H}_{2} \mathrm{O}$ (oxalato de manganês monoidratado) - validado pela IMA em 2004. Sistema Monoclínico. Massa molar $=185,59 \mathrm{~g} \cdot \mathrm{mol}^{-1}, \mathrm{com}$ 2,34 \% de hidrogênio. Aspecto dos cristais: prismáticos, com coloração variável entre o branco e o branco-acinzentado. Ambiente gerador: mineral secundário em pegmatitos graníticos, além de pseudomorfose em humboldtina, em associação com rockbridgeíta, trifilita, fosfossiderita, frondelita, strengita, cyrilovita, hureaulita, reddingita, tavorita, heterosita, laueíta e bermanita. Principais ocorrências: mina Boca Rica, Galiléia, Minas Gerais, Brasil; mina Molinello, Vale de Gravaglia, Gênova, Ligúria, Itália; Faletta e Parsettens, Grisões, Suiça; mina Lecht, Escócia. Usos do correspondente sintético: idênticos aos de caoxita (Lethbridge et al. 2003, Walenta 2003 in Jambor e Roberts 2004, Atencio 2004, Atencio et al. 2004, Back e Mandarino 2008).

\section{Melita}

$\mathrm{Al}_{2}\left[\mathrm{C}_{6}(\mathrm{COO})_{6}\right] \cdot 16 \mathrm{H}_{2} \mathrm{O}$ (melato de alumínio 
16-hidratado - Figura 3) - validado pré-IMA (descoberto em 1793). Sistema Tetragonal. Massa molar $=534,47$ g.mol ${ }^{-1}$, com 9,05 \% de hidrogênio. Aspecto dos cristais: bipiramidados, prismáticos, nodulares, maciços, finamente granulados, com coloração variável do castanho, branco-acastanhado, incolor, amarelo ao castanho-dourado. Ambiente gerador: mineral secundário em depósitos de linhito, sendo o alumínio derivado das argilas. Principais ocorrências: Artern, Turíngia e Bitterfeld, Saxônia-Anhalt, Alemanha; Lusice, Bilin, Valshov, Boskovice, República Tcheca; mina de Csordakúti, Tartabânia, Fejér, Hungria; Malevka, Bogoroditsk, Tula, Rússia. Usos do correspondente sintético: indústria farmacêutica em xaropes (Jobbins et al. 1965, Giacovazzo et al. 1973, Mandarino e Back 2004, Back e Mandarino 2008).

\section{Minguzzita}

$\mathrm{K}_{3} \mathrm{Fe}^{3+}\left(\mathrm{C}_{2} \mathrm{O}_{4}\right)_{3} \cdot 3 \mathrm{H}_{2} \mathrm{O}$ (oxalato de potássio e ferro triidratado) - validado pré-IMA (descoberto em 1955). Sistema Monoclínico. Massa molar = 491,25 g.mol-1 , com 1,23 \% de hidrogênio. Aspecto dos cristais: tabulares, com coloração variável do verde ao amarelo-esverdeado. Ambiente gerador: em ambientes limonitizados (oxidação em zonas de calcários dolomíticos), em associação com humboldtina e goethita. Principal ocorrência: Capo Calamita, ilha de Elba, Toscana, Itália. Usos do correspondente sintético: idênticos aos de caoxita (Fleischer 1956, Herpin 1958, Mandarino e Back 2004, Atencio 2004, Back e Mandarino 2008).

\section{Moolooíta}

$\mathrm{Cu}^{2+}\left(\mathrm{C}_{2} \mathrm{O}_{4}\right) \cdot \mathrm{nH}_{2} \mathrm{O}$ (oxalato de cobre hidratado) - validado pela IMA em 1986. Sistema Ortorrômbico. Massa molar $=160,57$ g. $\mathrm{mol}^{-1}$, com $0,63 \%$ de hidrogênio. Aspecto dos cristais: incrustrações com coloração variável do azul ao verde. Ambiente gerador: afloramentos de sulfetos de cobre venulares, em associação com quartzo, sampleíta, libethenita, calcopirita, digenita e covellita e, secundariamente, brochantita, antlerita, atacamita, gipsita, barita e jarosita. $\mathrm{O}$ mineral se forma pela reação entre excrementos de pássaros e soluções provenientes da oxidação dos minerais secundários no ciclo supergênico. Principais ocorrências: estação de Mooloo Downs, Bunbury Well, Austrá-
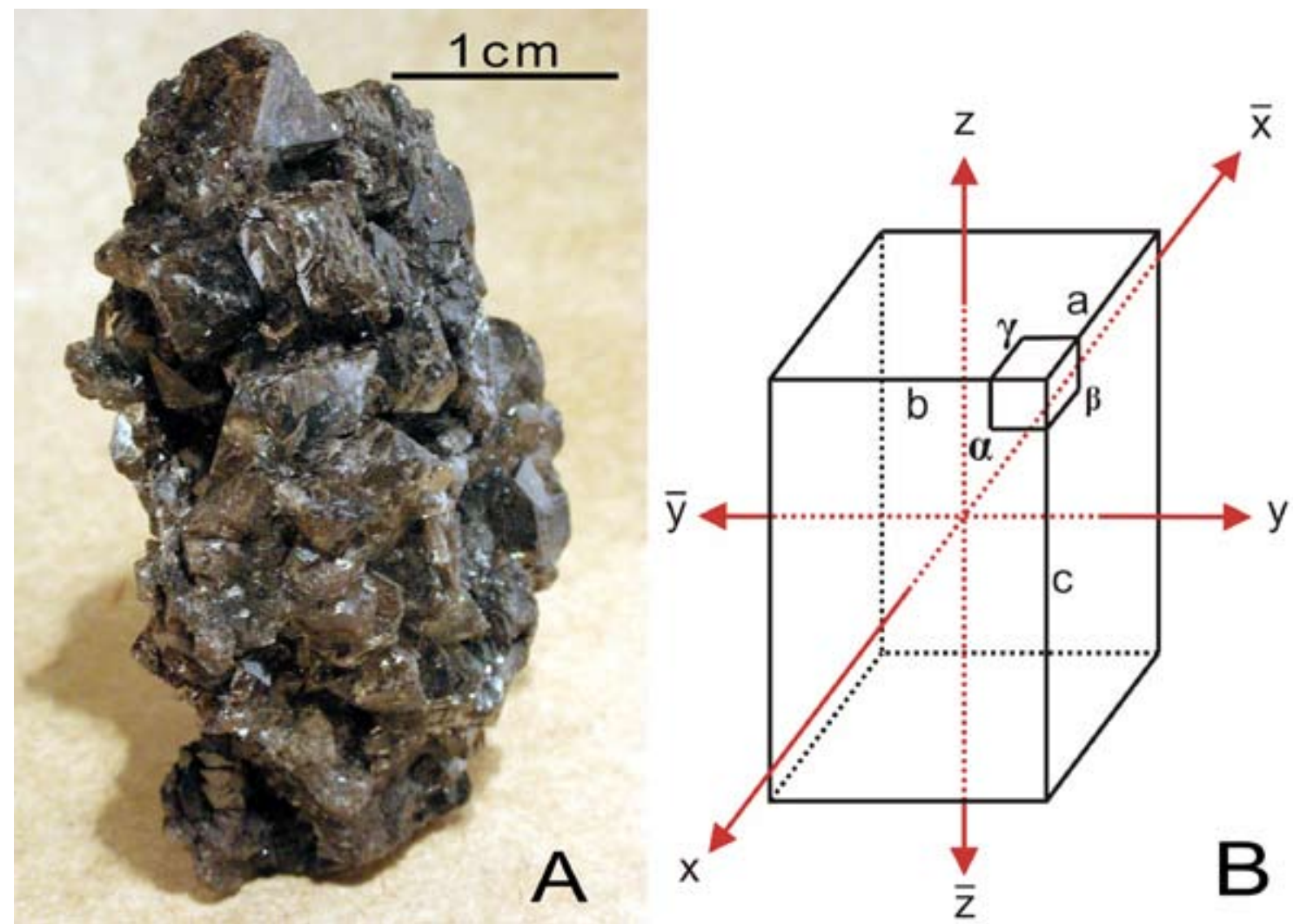

Figura 3 - Cristais de melita, mina de Csordakúti, Tartabânia, Fejér, Hundria (CMULBRA 00742) (A), modelo de sua cela unitária e constantes cristalográficas (B) (Laboratório de Geologia e Mineralogia, Curso de Química, ULBRA) 
lia; Ibergstausee, Stempeda, Turíngia, Alemanha; mina Sarbai, Rudnyi Altai, Cazaquistão; mina de prata de Sainte-Marie-aux-Mines, montanhas Vosgues, França. Usos do correspondente sintético: idênticos aos de caoxita (Clarke e Williams 1986, Hawthorne et al. 1987, Mandarino e Back 2004, Atencio 2004, Back e Mandarino 2008).

\section{Novgorodovaíta}

$\mathrm{Ca}_{2}\left(\mathrm{C}_{2} \mathrm{O}_{4}\right) \mathrm{Cl}_{2} \cdot 2 \mathrm{H}_{2} \mathrm{O}$ (cloro-oxalato de cálcio diidratado) - validado pela IMA em 2000. Sistema Monoclínico. Massa molar $=278,57 \mathrm{~g} \cdot \mathrm{mol}^{-1}, \mathrm{com}$ $1,66 \%$ de hidrogênio. Aspecto dos cristais: aglomerados cristalinos incolores. Ambiente gerador: depósitos evaporíticos de origem marinha, em associação com anidrita, boracita, bischofita, carnallita, halita, hidroboracita, hilgardita e magnesita. Principal ocorrência: domo salino de Chelkar, depressão do mar Cáspio, Cazaquistão. Usos do correspondente sintético: idênticos aos de caoxita (Mandarino e Back 2004, Atencio 2004, Back e Mandarino 2008, http://webmineral.com/data/ novgorodovaite. shtml).

\section{Oxamita}

$\left(\mathrm{NH}_{4}\right)_{2} \mathrm{C}_{2} \mathrm{O}_{4} \cdot \mathrm{H}_{2} \mathrm{O}$ (oxalato de amônio monoidratado) - validado pré-IMA (descoberto em 1870). Sistema Ortorrômbico. Massa molar $=142,11$ g. $\mathrm{mol}^{-1}$, com 1,42 \% de hidrogênio. Aspecto dos cristais: granulares, maciços, pulverulentos com coloração variável do branco ao branco-amarelado. Ambiente gerador: mineral derivado dos depósitos de guano, encontrado em ovos e ossos de subfósseis relativos a pássaros do Recente, em associação com mascagnita, aphthitalita e arcanita. Principais ocorrências: ilhas Guanapé, Departamento da Liberdade, Peru; caverna Petrogale, Austrália do Oeste, Austrália. Usos do correspondente sintético: idênticos aos de caoxita (Winchell e Benoit 1951, Taylor e Sabine 1972, Mandarino e Back 2004, Atencio 2004, Back e Mandarino 2008).

\section{Paceíta}

$\mathrm{CaCu}\left(\mathrm{CH}_{3} \mathrm{COO}\right)_{4} \cdot 6 \mathrm{H}_{2} \mathrm{O}$ (acetato de cálcio e cobre hexaidratado) - validado pela IMA em 2002. Sistema Tetragonal. Massa molar $=447,89 \mathrm{~g} \cdot \mathrm{mol}^{-1}$, com 5,40 \% de hidrogênio. Aspecto dos cristais: prismáticos, incrustrações agregadas sobre a matriz com coloração azul-escura. Ambiente gerador: mineral secundário formado por reação de oxidação entre minerais metálicos e matéria orgânica proveniente de folhas vegetais mortas, em associação com hoganita, linarita, malaquita, azurita, smithsonita, cerussita, goethita, hematita e quartzo.
Principal ocorrência: depósito de $\mathrm{Ag}-\mathrm{Pb}-\mathrm{Zn}$ de Potosi, Broken Hill, Nova Gales do Sul, Austrália. Usos do correspondente sintético: experimentos didáticos (soluções), soluções químicas para fertilidade de solos (Hibbs et al. 2002, Klop et al. 1983, van Raij et al. 2001, Mandarino e Back 2004, Back e Mandarino 2008).

\section{Ravatita}

$\mathrm{C}_{14} \mathrm{H}_{10}$ (fenantreno) - validado pela IMA em 1993. Sistema Monoclínico. Massa molar: 178,23 g.mol ${ }^{-1}$, com 5,60 \% de hidrogênio. Aspecto dos cristais: agregados placóides com coloração variável do incolor, branco ao cinza-claro. Ambiente gerador: sublimação por combustão natural em depósitos carboníferos, em associação com selênio nativo. Principais ocorrências: Ravat, bacia de FanYagnob, Tadjiquistão; mina Carola, Freital, Dresden, Saxônia, Alemanha. Usos: somente a forma natural é utilizada como material museológico e em coleções de minerais (Nasdala e Pekov 1993, Jambor e Grew 1994, Mandarino e Back 2004, Back e Mandarino 2008).

\section{Refikita}

$\mathrm{C}_{20} \mathrm{H}_{32} \mathrm{O}_{2}$ ( $\delta$-13-diidro-ácido pirâmico) - validado pré-IMA (descoberto em 1852). Sistema Ortorrômbico. Massa molar: 304,47 g. mol $^{-1}$, com $10,59 \%$ de hidrogênio. Aspecto dos cristais: aciculares com coloração branca. Ambiente gerador: resina ácida cristalizada a partir de raízes fósseis de abeto. Principais ocorrências: Montório al Vonamo, Teramo, Abruzzi, Itália; sul da Bavária, Alemanha. Usos: somente a forma natural é utilizada como material museológico e em coleções de minerais (Fleischer 1965, Strunz e Contag 1965, Mandarino e Back 2004, Back e Mandarino 2008).

\section{Simonellita}

$\mathrm{C}_{19} \mathrm{H}_{24}$ (1,1-dimetil-isopropil-1,2,3,4-tetraidrofenantreno) - validado pré-IMA (descoberto em 1919). Sistema Ortorrômbico. Massa molar: 252,40 g. $\mathrm{mol}^{-1}$, com 9,58 \% de hidrogênio. Aspecto dos cristais: incrustrações brancas. Ambiente gerador: linhito e rochas sedimentares ricas em matéria orgânica recobrindo madeira fossilizada, em associação com hartita. Principal ocorrência: Fognano, Montepulciano, Siena, Toscana, Itália. Usos do correspondente sintético: indústria farmacêutica (Holden 1922, Mandarino e Back 2004, Bonato e Jabor 2005, Back e Mandarino 2008, http://www. mindat.org/min-3666.html).

\section{Stepanovita}

$\mathrm{NaMgFe}^{3+}\left(\mathrm{C}_{2} \mathrm{O}_{4}\right)_{3} \cdot 8-9 \mathrm{H}_{2} \mathrm{O}$ (oxalato de sódio, 
magnésio e ferro octa-eneaidratado) - validado pré-IMA (descoberto em 1953). Sistema Trigonal. Massa molar: 520,33 g.mol ${ }^{-1}$, com 3,29 \% de hidrogênio. Aspecto dos cristais: aciculares, fibrosos, agregados granulares anédricos com coloração variável do verde ao amarelo-esverdeado. Ambiente gerador: cristalizado a partir de soluções aquosas, em associação com calcita, dolomita, whewellita e weddelita. Principal ocorrência: depósitos carboníferos de Tyllakh, foz do Lena, Yakutia, Chai-Tumus, Sakha, Sibéria, Rússia. Usos do correspondente sintético: idênticos aos de caoxita (Fleischer 1964, Mandarino e Back 2004, Atencio 2004, Back e Mandarino 2008).

\section{Uréia}

$\mathrm{CO}\left(\mathrm{NH}_{2}\right)_{2}$ (diamino de carbonila ou aminometanamida (Fig. 4) - validado pela IMA em 1972. Sistema Tetragonal. Massa molar: 60,06 g. $\mathrm{mol}^{-1}$, com $6,71 \%$ de hidrogênio. Aspecto dos cristais: piramidados, estalagmíticos, maciços com coloração variável entre o amarelo-claro e o castanho-claro. Os cristais sintéticos são brancos. Ambiente gerador: cristaliza em ambientes muito áridos, sendo proveniente de excremento e urina de quirópteros, em associação com aphthitalita, fosfamita e weddelita. Principal ocorrência: Lake Rason, cavernas Toppin Hill e Wilgie Mia, Kalgoorlie, Austrália do Oeste, Austrália. Usos do correspondente sintético: composto medicinal (carbamida), responsável pelo metabolismo proteíco (Bridge 1973b, Fleischer 1974, Swaminathan et al. 1984, Mandarino e Back 2004, Back e Mandarino 2008).

\section{Uricita}

$\mathrm{C}_{5} \mathrm{H}_{4} \mathrm{~N}_{4} \mathrm{O}_{3}$ (2,6,8-triidroxipurina ou ácido úri- co anidro) - validado pela IMA em 1973. Sistema Monoclínico. Massa molar: 168,11 g.mol ${ }^{-1}$, com 2,40 \% de hidrogênio. Aspecto dos cristais: massas pulverulentas com coloração variável entre o incolor e o branco-amarelado. Ambiente gerador: acúmulo de excrementos de pássaros marinhos e quirópteros em cavernas, podendo estar em associação com bifosfamita, brushita e singenita. Principais ocorrências: caverna de Dingo Donga, Rawlinna, Madura Motel, Eucla, Austrália do Oeste, Austrália; costa do Peru. Usos: somente a forma natural é utilizada como material museológico e em coleções de minerais (Reingertz 1966, Bridge 1974, Mandarino e Back 2004, Back e Mandarino 2008).

\section{Weddelita}

$\mathrm{Ca}\left(\mathrm{C}_{2} \mathrm{O}_{4}\right) \cdot 2 \mathrm{H}_{2} \mathrm{O}$ (oxalato de cálcio diidratado) - validado pré-IMA (descoberto em 1942). Sistema Tetragonal. Massa molar: 164,13 g.mol-1 ${ }^{-1}$, com 2,46 $\%$ de hidrogênio. Aspecto dos cristais: agregados, bipirâmides com coloração variável desde o incolor, bronze, branco, castanho ao castanho-amarelado. Ambiente gerador: mineral autigênico em sedimentos de fundo marinho, turfeiras, calcários lacustrinos e, também, formado pela reação de calcita com ácido oxálico derivado de líquens e soluções provenientes do guano de quirópteros, em associação com whewellita, uréia, fosfamita e aphthitalita. É um dos principais componente dos cálculos renais. Principais ocorrências: mar de Weddel, na Antártica; ilhas Geórgia do Sul, no Oceano Atlântico Sul; sedimentos de fundo do mar do Japão e do mar de Coral, no Oceano Pacífico; pedreira de Milltown, Derbyshire, Inglaterra; cavernas de Jingemia, Toppin Hill e Petrogale, Ma-
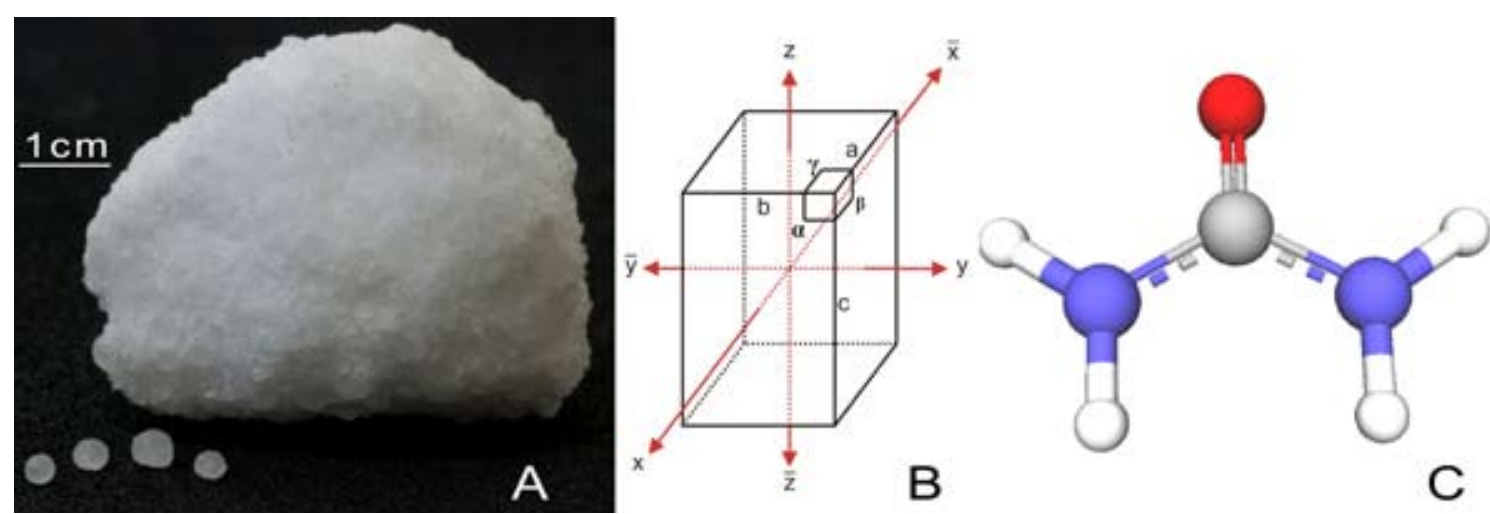

Figura 4 - Cristais sintéticos de uréia (CMULBRA 00784) (A), modelo de sua cela unitária com constantes cristalográficas (B) e modelo da molécula do diamino de carbonila (aminometanamida) (C) (Laboratório de Geologia e Mineralogia, Curso de Química, ULBRA) 
dura Motel, Austrália do Oeste, Austrália; depósito carbonífero de Tyllakh, foz do Lena, Sakha, Sibéria, Rússia; Saguenay, Cabo Herschel, Territórios do Noroeste, Canadá; mina de jaspe de Sami Tsubota, Biggs, Sherman, Oregon, Estados Unidos da América. Usos do correspondente sintético: idênticos aos de caoxita (Tazzoli e Domeneghetti 1980, van de Vijver et al. 1997, Mandarino e Back 2004, Atencio 2004, Branco e Chaves 2006, Back e Mandarino 2008).

\section{Wheatleyíta}

$\mathrm{Na}_{2} \mathrm{Cu}^{2+}\left(\mathrm{C}_{2} \mathrm{O}_{4}\right)_{2} \cdot 2 \mathrm{H}_{2} \mathrm{O}$ (oxalato de sódio e cobre diidratado) - validado pela IMA em 1986. Sistema Triclínico. Massa molar: 321,60 g. $\mathrm{mol}^{-1}$, com $1,25 \%$ de hidrogênio. Aspecto dos cristais: agregados aciculares azuis. Ambiente gerador: depósitos de $\mathrm{Pb}-\mathrm{Zn}$ (veios), em associação com galena, esfalerita, cerussita e quartzo. Principal ocorrência: mina de Wheatley, Phoenixville, Pensilvânia, Estados Unidos da América. Usos do correspondente sintético: idênticos aos de caoxita (Gleizes et al. 1980, Rouse et al. 1986, Mandarino e Back 2004, Atencio 2004, Back e Mandarino 2008).

\section{Whewellita}

$\mathrm{CaC}_{2} \mathrm{O}_{4} \cdot \mathrm{H}_{2} \mathrm{O}$ (oxalato de cálcio monoidratado) - validado pré-IMA (descoberto em 1852). Sistema Monoclínico. Massa molar: 146,11 g.mol ${ }^{-1}$, com 1,38\% de hidrogênio. Aspecto dos cristais: granulares, botrioidais, globulares, prismáticos, nodulares (formam septárias) de coloração variável desde o incolor, acastanhado, cinza, amarelo ao amareloacinzentado. Ambiente gerador: depósitos hidrotermais de baixa temperatura na zona de contato com litologias carboníferas ricas em metano e em grafita xistos, podendo estar em associação com calcita, barita, dolomita e pirita. Pode também ocorrer em depósitos uraníferos. Principais ocorrências: depósito antracítico da bacia de Doehlener, Freital e Burgk, Dresden, Saxônia e Shaft 21, Schlema, Hartenstein, Alemanha; Milan, Erie, Ohio, Estados Unidos da América. Usos do correspondente sintético: idênticos aos de caoxita. É uma substância responsável pela formação de cálculos renais (Leavens 1968, Tazzoli e Domeneghetti 1980, Mandarino e Back 2004; Atencio 2004, Branco e Chaves 2006, Back e Mandarino 2008).

\section{Zhemchuzhnikovita}

$\mathrm{NaMg}\left(\mathrm{Al}, \mathrm{Fe}^{3+}\right)\left(\mathrm{C}_{2} \mathrm{O}_{4}\right)_{3} \cdot 8-9 \mathrm{H}_{2} \mathrm{O}$ (oxalato de sódio, magnésio e alumínio octa-eneaidratado) - validado pela IMA em 1963. Sistema Trigonal. Massa molar: 494,00 g.mol-1 ${ }^{-1}$ com 3,26\% de hidro- gênio. Aspecto dos cristais: aciculares, fibrosos com coloração variável do verde-acinzentado ao violeta. Ambiente gerador: minas de linhito e carvão mineral em locais saturados por ácido acético, estando em associação com calcita, dolomita e stepanovita. Principal ocorrência: depósitos carboníferos de Chaitumussk, Yakutia, Sibéria, Rússia. Usos do correspondente sintético: idênticos aos de caoxita (Fleischer 1962, Fleischer 1964, Mandarino e Back 2004, Atencio 2004, Back e Mandarino 2008).

\section{Zugshunstita - (Ce)}

$(\mathrm{Ce}, \mathrm{Nd}, \mathrm{La}) \mathrm{Al}\left(\mathrm{SO}_{4}\right)_{2}\left(\mathrm{C}_{2} \mathrm{O}_{4}\right) \cdot 12 \mathrm{H}_{2} \mathrm{O}$ (aluminossulfo-oxalato de cério dodecaidratado) - validado pela IMA em 1996. Sistema Monoclínico. Massa molar $=667,51 \mathrm{~g} \cdot \mathrm{mol}^{-1}, \operatorname{com} 3,62 \%$ de hidrogênio. Aspecto dos cristais: agregados irregulares, prismáticos com coloração variável do rosa ao azul-pálido. Ambiente gerador: mineral supergênico formado por alteração de filitos piritosos, sendo as terras raras, possivelmente, derivadas das monazitas e xenotímios, estando em associação com levinsonita-(Y), epsomita e halotriquita. Principal ocorrência: Alum Cave Bluff, Great Smoky Mountains National Park, Servier, Tennessee, Estados Unidos da América. Usos do correspondente sintético: idênticos aos de caoxita (Crosken e Lauf 2000, Rouse et al. 2001, Mandarino e Back 2004, Atencio 2004, Back e Mandarino 2008).

\section{CONCLUSÕES}

O grupo componente da classe mineralógica das combinações orgânicas apresenta um conjunto de minerais que estão entre as substâncias químicas naturais de mais rara ocorrência na Terra, tais como a abelsonita, a calclacita, a caoxita, a coskrenita-(Ce), a dashkovaíta, a earlandita, a evenkite, a flagstaffita, a hoganita, a kratochvilita, a levinsonita-(Y), a minguzzita, a novgodorovaíta, a paceíta, a refikita, a simonellita, a stepanovita, a uréia, a wheatleyíta, a zhemchuzhnikovita e a zugshuntita-(Ce), todas pontuais na distribuição de seus diminutos depósitos.

A maioria dessas substâncias apresenta importância industrial significativa em seus correspondentes sintéticos, principalmente nas indústrias farmacêutica e química, como os oxalatos, as amidas, os formiatos, os acetatos, o fluoreno, a níquel-porfirina, o coroneno, o citrato, a purina, o diperteno, a antraquinona, a ftalimida, o melato e o 
fenantreno. Apresentam aplicações diversas como: metalizadores, plastificadores, nanotecnologia, nutrientes, tratamento de águas, revestimento de válvulas, medicamentos (anti-fungicidas, antibióticos e xaropes), aditivantes em cosméticos, tintas metálicas e plásticos, agente exobiológico, catalisadores, agentes oxidantes e anti-corrosivos, fonte de cobre em síntese orgânica, pigmentos, fertilizadores de solos e metabolizadores, entre outras.

Todos os minerais desta classe, devido à raridade, são extremamente importantes sob o ponto de vista científico e como amostras para coleções de minerais, de museus e particulares. As espécies caoxita, weddelita, acetamida, whewellita, earlandita e carpatita, merecem atenção especial em geomedicina por serem agentes carcinogênicos, acumuladores de cálculos renais no sistema urinário e tóxicos para o epitélio e DNA dos mamíferos em geral.

Apenas duas espécies apresentam registro para o Brasil, humboldtina e lindbergita, ambas com ocorrência em depósitos pegmatíticos de Minas Gerais.

O mineral evenkita, $\mathrm{C}_{24} \mathrm{H}_{50}$, é entre os minerais que apresentam hidrogênio em suas composições químicas, o que tem a maior massa no elemento, com 14,88 \%. Até o momento foram descritos 2370 minerais com hidrogênio (num universo em torno de 4500 substâncias) em suas composições químicas. A classe das combinações orgânicas é composta por apenas 41 minerais, sendo que somente o natroxalato $\left(\mathrm{Na}_{2} \mathrm{C}_{2} \mathrm{O}_{4}\right)$ não apresenta $\mathrm{o}$ elemento hidrogênio.

\section{Referências bibliográficas}

Abell G.O., Morrison D., Wolff S.C. 1985. Exploration of the Universe. Philadelphia: Saunders. $755 \mathrm{p}$.

Atencio D. 2004. Coutinhoíta e lindbergita: mineralogia aplicada. In: CONGRESSO BRASILEIRO DE GEOLOGIA, 2004, 42. Anais..., Araxá (MG): SBGeo. S25-T24 (CD-ROM).

Atencio D., Coutinho J.M.V., Graesner S., Matioli P.A., Menezes Fo L.A.D. 2004. Lindbergite, a new manganese oxalate dihydrate from Boca Rica mine, Galiléia, Minas Gerais, Brazil, and Parsettens, Oberhalbstein, Switzerland. Am. Mineral., 89(7):1087-1091.

Back M.E., Mandarino J.A., 2008. Fleischer's glossary of Mineral Species. Tucson: The Mineralogical Record, 343p.
Barrow J. 1994. The origin of the Universe. Sussex: Orion Publ. 124p.

Basso R., Lucchetti G., Zefiro L., Palenzona A. 1997. Caoxite, $\mathrm{Ca}\left(\mathrm{H}_{2} \mathrm{O}\right)_{3}\left(\mathrm{C}_{2} \mathrm{O}_{4}\right)$, a new mineral from the Cerchiara mine, northern Appennines, Italy. Neues Jahrb. Mineral., Monats., 84-96.

Betejtin A. 1970. Curso de Mineralogia. Moscou: MIR. $739 \mathrm{p}$.

Bonato P.S., Jabor V.A.P. 2005. Análise enantiosseletiva de fármacos: contribuições da cromatografia líquida de alta eficiência e eletroforese capilar. Quím. Nova, 28(4):683-691.

Bouska V., Cisarova I., Skala R., Dvorak Z., Zelinka J., Zak K. 1998. Hartite from Bílina. Am. Mineral., 83(11-12):1340-1346.

Branco P.M., Chaves M. L. S. C. 2006. A mineralogia e alguns de seus minerais raros ou de gênese exótica. Terrae Didatica, 2(1):75-85. URL: < http:// www.ige.unicamp.br/terraedidatica/ $>$ /acesso em 03.03.2008.

Bridge P. J. 1973a. Guano minerals from Murrael-Elevyn cave, Western Australia. Min. Mag., 39:467-469.

Bridge P.J. 1973b. Urea, a new mineral and neotype phosphammite from Western Australia. Min. Mag., 39:346-348.

Bridge P. J. 1974. Guanine and uricite, two new organic minerals from Peru and Western Australia. Min. Mag., 39:889-890.

Brow G. M., Bortner M. H. 1954. On the crystal and molecular structure of fluorene. Ac. Cryst., 7:139.

Clarke R. M., Williams I. R. 1986. Moolooite, a naturally occurring hydrated copper oxalate from Western Australia. Min. Mag., 50:295-298.

Cordani H. G. 2003. O Planeta Terra e suas Origens. In: Teixeira W., Toledo, M. C. M. de, Fairchild T. R., Taioli F. orgs. 2003. Decifrando a Terra. São Paulo: Oficina de Textos. p.1-26.

Cotton F. A., Wilkinson G. 1988. Advanced Inorganic Chemistry. New York: John Wiley, 1445p.

Cowgill U. M. 1989. A naturally occurring alpha magnesium oxalate dehydrate from northern Jordan Valley (Israel). Min. Mag., 53:505-507.

Crosken T. D., Lauf R. J. 2000. The minerals of Alum Cave Bluff, Great Smoky Mountains, Tennessee. Min. Rec., 31:163-175.

Denne W. A., Small R. W. H. 1971. A refinement of the structure of rhombohedral acetamide Ac. Cryst., 
B27:1094-1098.

Echigo T., Kimata M., Maruoka T. 2007. Crystalchemical and carbon-isotopic characteristics of karpatite $\left(\mathrm{C}_{24} \mathrm{H}_{12}\right)$ from the Picacho Peak Area, San Benito County, California: Evidences for the hydrothermal formation. Am. Mineral., 92(89):1262-1269.

Emiliani C. 1995. Plantet Earth. Cosmology, geology, and the evolution of life and environment. New York: Cambridge Un. Press. 718p.

Engel R. 1896. Traité Élémentaire de Chimie. Paris: Librairie J.-B. Bailliére, 364p.

Fleischer M. 1946. New Mineral Names. Am. Mineral., 31(11-12):605-606.

Fleischer M. 1947. New Mineral Names. Am. Mineral., 32(3-4):254-255.

Fleischer M. 1955. New Mineral Names. Am. Mineral., 40(3-4):367-370.

Fleischer M. 1956. New Mineral Names. Am. Mineral., 41(3-4):370-371.

Fleischer M. 1957. New Mineral Names. Am. Mineral., 42(1-2):117-124.

Fleischer M. 1962. New Mineral Names. Am. Mineral., 47(11-12):1482-1485.

Fleischer M. 1964. New Mineral Names. Am. Mineral., 49(3-4):439-448.

Fleischer M. 1965. New Mineral Names. Am. Mineral., 50(11-12):2096-2111.

Fleischer M. 1974. New Mineral Names. Am. Mineral., 59(7-8):873-875.

Fleischer M. 1976. New Mineral Names. Am. Mineral., 61:338-341.

Fleischer M., Pabst A. 1981. New Mineral Names New Data. Am. Mineral., 66(3-4):436-439.

Fleischer M., Chao G. Y., Mandarino, J. A. 1976. New Mineral Names. Am. Mineral., 61(3-4):338-341.

Giacovazzo C., Menchetti S., Scordari F. 1973. The crystal structure of mellite. Ac. Cryst., B29:2631.

Gleizes A., Maury F., Galy J. 1980. Crystal structure and magnetism of sodium bi (oxalate) cuprate (II) dehydrate, $\mathrm{Na}_{2} \mathrm{Cu}\left(\mathrm{C}_{2} \mathrm{O}_{4}\right)_{2} \cdot 2 \mathrm{H}_{2} \mathrm{O}$. Inorg. Chem., 19:2074-2078.

Gonçalves, J. C. 2003. Tabela Atômica - um estudo completo da Tabela Periódica. Curitiba: Atômica. 263p.

Greenwood N.N., Earnshaw A. 2006. Chemistry of the elements. Amsterdam: Elsevier. 1341p.

Guild F.N. 1920. Flagstaffite, a new mineral from Arizona. Am. Mineral., 5(10):169-172.
Guild F.N. 1921. The identity of flagstaffite and terpin hydrate. Am. Mineral., 6(9):133-134.

Hawthorne F., Jambor J.L., Bladh K.W., Burke E.A.J., Grice J.D., Phillips D., Roberts A.C., Schadler R., Shigley J. 1987. New Mineral Names. Am. Mineral., 72(9-10):1023-1028.

Herpin P. 1958. Structure crystalline des trioxalates complexes of potassium. Bull. Mineral., 81:245256.

Hibbs D.E., Kolitsch U., Leverett P., Sharpe J.L., Williams P.A. 2002. Hoganite and paceite, two new acetate minerals from the Potosi mine, Broken Hill, Australia. Min. Mag., 66:459-464.

Hoelite, http://www.mindat.org/min-1915.html/acesso em 03.03.2008.

Holden E.F. 1922. Notes and News. Am. Mineral., 7(10):178.

Hollis J.M., Lovas F.J., Remijan A.J., Jewell P.R., Ilyushin V.V., Kleiner I. 2006. Detection of acetamide $\left(\mathrm{CH}_{3} \mathrm{CONH}_{2}\right)$ : the largest interstellar molecule with a peptide bond. The Astrophys. J., 643(1):25-28.

Ionescu L., Neves P.C.P.das, Schenato F., Bachi F. A. 2007. The Periodic Table of the Elements and the associated minerals: gold. South Braz. J. Chem., 15(15):1-13.

Jambor J.L., Grew E. S. 1994. New Mineral Names. Am. Mineral., 79(3-4):387-391.

Jambor J.L., Roberts A.C. 2001. New Mineral Names. Am. Mineral., 86(11-12):1534-1536.

Jambor J.L., Roberts A.C. 2004. New Mineral Names. Am. Mineral., 89(11-12):1826-1834.

Jambor J.L., Roberts A.C. 2005. New Mineral Names. Am. Mineral., 90(1): 271-275.

Jambor J.L., Grew E.S., Roberts A.C. 1998. New Mineral Names. Am. Mineral., 83(1-2):185-189.

Jambor J.L., Pertsev N.N., Roberts A.C. 2000a. New Mineral Names. Am. Mineral., 85(9):1321-1326.

Jambor J.L., Grew E.S., Roberts A.C. 2000b. New Mineral Names. Am. Mineral., 85(10):185-189.

Jambor J.L., Grew E.S., Roberts A.C. 2004. New Mineral Names. Am. Mineral., 89(10):1561-1565.

Jambor J.L., Grew E.S., Roberts A.C. 2005. New Mineral Names. Am. Mineral., 90(3):518-522.

Jehlica J., Edwards H. G. M., Zacek V. 2008. Organic minerals and their direct nondestructive detection in rocks using Raman spectroscopy - possible use in exobiological studies. Geoph. Res. Abst., (10), EGU 2008-A-02180, EGU General Assembly, Prague. 
Jobbins E.A., Sergeant G.A., Young B. R. 1965. X-ray and other data for mellite. Min. Mag., 35:542544.

Kennedy G.L., Sherman H. 1986. Acute and subchronic toxity of dimetilformamide and dimethylacetamide following various routes of administration. Drug and Chem. Toxicol., 9(2):147-170.

Khan S.R., Opalko F.J., Adair J.H. 1997. Heterogeneous nucleation of calcium oxalate trihydrate in artificialurine by constant composition. J. Cryst. Growth, 181(4):410-417.

Kirchner S.J., Fernando, Q. 2000. Copper(I) acetate. Inorg. Synth., 20:53-55.

Klein C. 2002. Mineral Science. New York: John Willey \& Sons, 681p.

Klein C., Hurlbut Jr. C.S. 1998. Manual of Mineralogy. New York: John Wiley and Sons, 683p.

Klop E.A., Duisenberg, A.J.M., Spek, A. L. 1983. Reinvestigation of the structure of calcium copper acetate hexahydrate, $\mathrm{CaCu}\left(\mathrm{C}_{2} \mathrm{H}_{3} \mathrm{O}_{2}\right)_{4} \cdot 6 \mathrm{H}_{2} \mathrm{O}$. $A c$. Crystal., C39:1342-1344.

Kratochvilite, http://rruff.geo.arizona.edu/doclib/ hom/kratochvilite.pdf/acesso em 27.02.2008.

Leavens P.B. 1968. New data on whewellite. Am. Mineral., 53(3-4):455-463.

Lee J.D. 2003. Química Inorgânica não tão concisa. São Paulo: Blücher, 527p.

Lethbridge Z.A.D., Congreve A.F., Esslemont E., Slawin A.M.Z., Lightfoot P. 2003. Synthesis and structure of three manganese oxalates: $\mathrm{MnC}_{2} \mathrm{O}_{4} \cdot 2 \mathrm{H}_{2} \mathrm{O}\left[\mathrm{C}_{4} \mathrm{H}_{8}\left(\mathrm{NH}_{2}\right)_{2}\right],\left[\mathrm{Mn}_{2}\left(\mathrm{C}_{2} \mathrm{O}_{4}\right)_{3}\right]$ and $\mathrm{Mn}_{2}\left(\mathrm{C}_{2} \mathrm{O}_{4}\right)(\mathrm{OH})_{2}$. J. Solid State Chem., 172:212218.

Linnow K., Halsberghe L., Steiger M. 2007. Analysis of calcium acetate efflorescenses formed on ceramic tiles in a museum environment. J. Cult. Herit., 8(1-3):44-52.

Locock A.J., Piilonen P., Scott Ercit T., Rowe R. 2006a. New Mineral Names. Am. Mineral., 91(1):216224.

Locock, A.J., Piilonen, P., Scott Ercit, T., Rowe, R., Kolitsch, R. 2006b. New Mineral Names. Am. Mineral., 91(4):710-715.

Locock A.J., Scott Ercit T., Kjellmann J., Piilonen P. 2006c. New Mineral Names. Am. Mineral., 91(1112):1945-1954.

Mace H.A., Peterson R.C. 1995. The crystal structure of fichtelite, a naturally occurring hydrocarbon. Can. Mineral., 33:7-11.

Mandarino J.A., Back M.E. 2004. Fleischer's glossary of
Mineral Species. Tucson: The Mineralogical Record, 309p.

Mason G.M., Trudell L.G., Branthaver J.F. 1989. Review of the stratigraphic distribution and diagenetic history of abelsonite. Org. Geochem., 14:585-594.

Mazat E. 1972. Die kristaalstruktur des phtalimids (kladnoite). Ac. Cryst., 28:415-418.

Mazzi F., Gavarelli C. 1957. La struttura della oxalate: $\mathrm{FeC}_{2} \mathrm{O}_{4} \cdot 2 \mathrm{H}_{2}$ O. Per. Mineral., 26:269-303.

Milovsky A.V., Kononov O.V. 1985. Mineralogy. MIR, Moscou, 320p.

Milton C., Dwornik E.J., Estep-Barnes P.A., Finkelman R. B., Pabst A., Palmer S. 1978. Abelsonite, nickel porphyrin, a new mineral from the Green River Formation, Utah. Am. Mineral., 63(9-10): 930-937.

Miyakawa K., Kobayashi K., Sawaoka, A. B. 2000. Abiotic synthesis of guanine with high-temperature plasma. Origin of the Life and Evolution of Biosphere, 30(6):557-566.

Nasdala L., Pekov I.V. 1993. Ravatite, $\mathrm{C}_{14} \mathrm{H}_{10}$, a new organic mineral species from Raval, Tadzhikistan. Eur. J. Mineral., 5:699-705.

Neves P.C.P. das, Schenato F., Bachi F.A. 2005. The chemical elements of the Periodic Table and the associated minerals - The silver. South. Braz. J. Chem., 13(13): 63-79.

Neves P.C.P. das, Bachi F.A., Prochnow E.A., Schenato F. 2006. O cobre e os minerais associados. Technol., 7(1):67-92.

Neves P.C.P. das, Schenato F. 2007. O chumbo e os minerais associados. Technol., 8(1):55-73.

Neves P.C.P. das, Schenato F., Vieira D. 2007. A platina e os minerais associados. Technol.. 8(2): 91-96.

Neves P. C. P. das, Schenato F., Bachi F.A. 2008a. Introdução à Mineralogia Prática. Canoas: ULBRA. $326 \mathrm{p}$.

Neves P.C.P. das, Corrêa D.S., Cardoso J.R. 2008b. O lítio e os minerais associados. Technol., 9(1), (no prelo).

Neves P. C. P. das, Corrêa D.S., Cardoso J.R. 2008c. O berílio e os minerais associados. Technol., 9(2), (no prelo).

Nickel E.H. 1985. The definition of a mineral. Can. Mineral., 33:689-690.

Novogorodovaíta, http://webmineral.com/data/Novgorodovaite.shtml/acesso em 21.02.2008.

Peacor D.R., Rouse R.C., Essene E.J. 1999. Coskrenite-(Ce) $(\mathrm{Ce}, \mathrm{Nd}, \mathrm{La})_{2}\left(\mathrm{SO}_{4}\right)_{2}\left(\mathrm{C}_{2} \mathrm{O}_{4}\right) \cdot 8 \mathrm{H}_{2} \mathrm{O}$, a new 
rare-earth oxalate mineral from Alum Cave Bluff, Tennessee: characterization and crystal structure. Can. Mineral., 37:1453-1462.

Piilonen P., Scott Ercit T., Roberts A.C. 2005a. New Mineral Names. Am. Mineral., 90(4):768-773.

Piilonen P., Grew E. S., Scott Ercit T., Roberts A.C., Jambor J.L. 2005b. New Mineral Names. Am. Mineral., 90(7):1227-1233.

Piilonen P., Locock A., Grew E.S. 2005c. New Mineral Names. Am. Mineral., 90(11-12):1945-1952.

Piilonen P., Rowe R., Scott Ercit T., Locock A.J. 2006. New Mineral Names. Am. Mineral., 91(89):1452-1457.

Piilonen P., Locock A.J., Rowe R., Scott Ercit T. 2007. New Mineral Names. Am. Mineral., 92(4):703707.

Pogaines E.M., Shaw E.H. 1957. The unit cell dimensions of tricalcium citrate tetrahydrite. Proc. South Dakota Ak. Scien., 37:56-59.

Poirier G., Piilonen P. 2007. New Mineral Names. Am. Mineral., 92(10):1776-1779.

Poirier G., Tait, K., Scott Ercit, T., Rowe, R, Piilonen, P. 2008. New Mineral Names. Am. Mineral., 93(4):702-706.

Reingertz, H. 1966. The molecular and crystal structure of uric acid. Ac. Crystal., 20:397-403.

Rouse R., Peacor D.R., Dunn P.J., Simmons W. B., Newberry D. 1986. Wheatleyite, $\mathrm{Na}_{2} \mathrm{Cu}\left(\mathrm{C}_{2} \mathrm{O}_{4}\right)_{2} \cdot 2 \mathrm{H}_{2} \mathrm{O}$, a natural sodium copper salt of oxalic acid. Am. Mineral., 71(9-10):12401242.

Rouse R.C., Peacor D.R., Essene E.J., Coskren T.D., Lauf R.J. 2001. The new minerals levinsonite-(Y) $\left[(\mathrm{Y}, \mathrm{Nd}, \mathrm{Ce}) \mathrm{Al}\left(\mathrm{SO}_{4}\right) 2\left(\mathrm{C}_{2} \mathrm{O}_{4}\right) \cdot 12 \mathrm{H}_{2} \mathrm{O}\right]$ and zugshunstite-( $\mathrm{Ce})$ [( $\mathrm{Ce}, \mathrm{Nd}, \mathrm{La})$ $\mathrm{Al}\left(\mathrm{SO}_{4}\right)_{2}\left(\mathrm{C}_{2} \mathrm{O}_{4}\right) \cdot 12 \mathrm{H}_{2} \mathrm{O}$ ]: coexisting oxalates with different structures and differentiation of REE and HREE. Geoch. Cosmoch. Ac., 65(2):1101-1115.

Scott Ercit T., Piilonen P., Locock A.J., Kolitsch U., Rowe R. 2006. New Mineral Names. Am. Mineral., 91(7):1201-1209.

Scott Ercit T., Piilonen P., Rowe R. 2007. New Mineral Names. Am. Mineral., 92(8-9):1539-1542.

Simoneit B.R.T., Feitzer J.C. 1996. High molecular weight polycyclic aromatic hydrocarbons in hydrothermal petroleums from the Gulf of California and Northeast Pacific Ocean. In: International meeting on organic geochemistry, 17, San
Sebastian, September, 1996. IMOG, Special Issues: (24):1065-1077.

Simonellita, http:/www.mindat.org/min-3666.html/ acesso em 25.02.2008.

Strunz H., Contag B. 1965. Evenkit, Flagstaffit, Idrialin und Reficit. Neues Jahrb. Mineral., Monats., 19-25.

Strunz H., Nickel E.H. 2001. Strunz mineralogical tables: chemical-structural mineral classification system. Stuttgart: Schweizerbart'sche, 870p.

Swaminathan S., Craven B.M., Mcmullan R.K. 1984. The crystal structure and molecular thermal motion of urea at 12,60 and $123 \mathrm{~K}$ from neutron diffraction. Ac. Cryst., 40:300-306.

Taylor J.C., Sabine T.M. 1972. Isotope and bonding effects in ammonium oxalate monohydrate, determined by the combined use of neutron and X-ray deffraction analyses. Ac. Crystal., B28:33403351.

Tait K., Poirier G., Rowe R., Piilonen P. 2008. New mineral names. Am. Mineral., 93(1):252-256.

Tazzoli V., Domeneghetti C. 1980. The crystal structure of whewellite and weddellite: re-examination and comparision. Am. Mineral., 65(3-4):327-334

Trevin S., Bedioui F., Devynch J. 1996. New electropolymerized nickel porphyrin films. Application to the detection of nitric oxid in aqueous solution. J. of Elect. Chem., 408(1):261-265.

van de Vijver B., Vochten R., Geys J., Verbruggen C., Beyens L. 1997. Mineralogical observations of weddellite from South Georgia, Subantarctica. Neues Jahrb. Mineral., Monat., 193-202.

van Raij B., Andrade J.C.de, Cantarella H., Quaggio J.A. 2001. Análise química para avaliação da fertilidade de solos tropicais. Instituto Agronômico: Campinas, 285p.

van Tassel R. 1958. On the crystallography of calclacite, $\mathrm{Ca}\left(\mathrm{CH}_{3} \mathrm{COO}\right) \mathrm{Cl} .5 \mathrm{H}_{2} \mathrm{O}$. Acta Cryst., 11:745746.

Wilsor M.J., Jones U.D., Russell J.D. 1980. Glushinskite, a naturally occurring magnesium oxalate. Min. Mag., 43:837-840.

Winchell H., Benoit R.J. 1951. Taylorite, mascagnite, aphthitalite, lecontite, and oxammite from guano. Am. Mineral., 36(7-8):590-601. 